\begin{tabular}{lll}
\hline Volume 04 & No. 01 & April 2016 \\
\hline
\end{tabular}

\title{
Analisis Strategi Pelayanan Geriatri Berbasis Rumah Sakit dengan Menggunakan Value Chain di Rumah Sakit Islam Kendal
}

\section{Analysis of Hospital-Based Geriatric Care Strategy Using ValueChain at the Islamic Hospital Kendal}

\author{
Sutanti Murti Handayani ${ }^{1}$, Sudiro' ${ }^{2}$, Ani Margawati ${ }^{2}$ \\ 1) Rumah Sakit Islam Kendal \\ Jl. Ar Rahmah No 17 Weleri Kendal \\ No. Telp (0294) 643756 \\ Email: tantiemha@yahoo.co.id \\ 2) Fakultas Kesehatan Masyarakat, Universitas Diponegoro, Semarang
}

\begin{abstract}
Abstrak
Peningkatan jumlah usia lanjut di Kabupaten Kendal berdampak pada kenaikan pasien geriatri di RSI Kendal namun belum terlayani secara holistik. Bisnis Plan tentang layanan unggulan geriatri belum jelas sehingga perlu dilakukan upaya untuk memberikan nilai tambah pada pelayanan.

Tujuan penelitian untuk menganalisis penerapan strategi value chain pada pelayanan rawat jalan geriatri yang berbasis rumah sakit di RSI Kendal. Jenis penelitian ini adalah kualitatif. Pengambilan data dengan tehnik wawancara mendalam. Subyek penelitian terdiri dari empat orang informan utama yaitu Direktur, Manager Pelayanan, Manager SDM, Kepala Ruang Rawat Jalan, sedangkan dua orang dokter spesialis , satu orang perawat poli Dalam dan satu perawat poli Syaraf sebagai informan triangulasi. Analisis data dilakukan dengan analisis isi.

Hasil penelitian menunjukkan bahwa kekuatan nilai pada pelayanan geriatri berada pada letak geografis, kepuasan pelayanan, mutu pelayanan yang didukung oleh budaya yang profesional serta sumber daya tehnologi untuk kelas C. Kelemahan nilainya terletak pada perawat pemberi pelayanan yang belum terstandar sebagai perawat gerontik dan belum adanya survey pasar pelayanan geriatri. Pelayanan geriatri masih dilayani dipoli penyakit dalam, syarat dan fisioterapi. Proses analisis pada relevansi kompetitif memberikan gambaran bahwa pelayanan geriatri memiliki nilai yang sangat dihargai, langka, sulit ditiru dan berkesinambungan.

Simpulan penelitian ini adalah pelayanan geriatri memiliki keunggulan kompetitif dan strategi yang dapat diterapkan adalah diferensiasi. Disarankan kepada manajemen untuk mengevaluasi bisnis plan dengan melakukan penelitian pasar dan perencanaan SDM marketing.
\end{abstract}

Kata kunci : Analisis, Value chain, strategi bisnis, geriatri, rumah sakit

\begin{abstract}
An increasing number of elderly peopel in Kendal district led to a rise in RSI Busines Plan of geriatric services have not been clearly superior to the Kendal geriatric patients but has not been served in a holistic manner. analysis of value chain in the pre service, point service, and after service in order to provide added value to the service as a competitive relevance as an input in determining the business strategy. The purpose of the study to analyze the application value chain strategies to service-based outpatient geriatric hospital in Kendal RSI.

The research is a qualitative with depth interview techniques. The subjects of the study consisted
\end{abstract}


of four main informants is Director, Service Manager, HR Manager, Head of Outpatient Installation, while two specialist doctors, one of interna's nurse and one of nurse In Neural's poli as informant triangulation.

The results showed that the strength of the value of the services geriatrics is at the geographical location, service satisfaction, quality of service, supported by a professional culture and technology resources for class $C$. The weakness lies in the value of nurses who have not been standardized service providers as a nurse gerontik and lack of care of the elderly market surveys. Care of the elderly is still served in outpatient poly and physiotherapy.

The process of competitive analysis on the relevance of the idea that the care of the elderly has a value that is greatly appreciated, rare, difficult to imitate and sustainable.

Conclusions This study is the care of the elderly have a competitive advantage and strategies that can be applied is differentiation. It is recommended to management to evaluate busines plan to conduct market research and marketing planning of human

Keywords : Analysis, Value chain, hospital-based care of the elderly

\section{PENDAHULUAN}

Meningkatnya jumlah usia lanjut di di kabupaten Kendal pada umumnya dan meningkatnya jumlah pasien yang berusia 60 tahun keatas, serta terus bertambahnya kasus geriatri di rumah RS Islam Kendal menjadikan salah satu alasan untuk membuka layanan geriatri. Pelayanan geriatri ini sudah ada didalam business plan RS Islam Kendal, namun belum dilakukan penelitian pasar yang mendalam dan pemasaran pelayanan geriatri. Dalam busisness plan juga belum memberikan rincian program pencapaian untuk layanan unggulan. Pelayanan geriatri tidak hanya pelayanan pada rawat jalan akan tetapi perlu pelayanan penunjang lainnya yang mendukung pelayanan geriatri tersebut. Pelayanan geriatri di RS Islam Kendal masih pada pelayanan penyakit dalam dan syaraf, sedangkan pelayanan penunjang lainnya masih berdiri sendiri. Dalam arti pelayanan geriatri di RS Islam Kendal belum dilayani secara holistik .Di satu sisi pelayanan yang berkaitan dengan penanganan usia lanjut di RS Islam Kendal memiliki data kenaikan yang terus meningkat secara significan. Mereka adalah pasien dengan keluhan sosio medis seperti hipertensi, diabetes dan lain lain ,akan tetapi di RS Islam Kendal pelayanan ini masih menjadi satu dengan pelayanan penyakit dalam. Sehingga pasien yang terus meningkat ini hanya ditangani secara klinis saja belum pada aspek psikisnya.

Evaluasi pelayanan yang telah berjalan dapat dilakukan dengan menggunakan analisa rantai nilai (Value chain). Analisis value chain diperlukan untukmelihat aktifitas pelayanan geriatri yang dimulai sebelum (pre service), saat pelayanan (point of service) dan sesudah pelayanan (after service) serta aktifitas pendukung pelayanan geriatri sehingga pelayanan geriatri merupakan layanan yang terintegrasi sejak sebelum ,saat hingga setelah pelayanan geriatri dilakukan.

\section{Value Chain Pada Pelayanan Rumah Sakit}

Model rantai nilai merupakan alat analisis yang berguna untuk mendefinisikan kompetensi inti perusahaan di mana perusahaan dapat mengejar keunggulan kompetitif sebagai berikut:

1. Keunggulan biaya dengan lebih baik, memahami biaya dan menekannya keluar dari aktivitas penambahan nilai.

2. Differensiasi dengan berfokus pada aktivitasaktivitas yang berhubungan dengan kompetensi inti dan kemampuan untuk melakukannya lebih baik daripada pesaing

Porter membagi aktivitas-aktivitas kedalam dua kategori. Pertama adalah primary activities (aktivitas primer), yaitu aktivitas yang berkaitan dengan penciptaan fisik produk, penjualan dan distribusinya ke para pembeli, dan layanan setelah penjualan. Support processes, yaitu aktivitas proses yang dari waktu ke waktu memberikan dukungan terhadap perusahaan dan secara tidak langsung memberikan kontribusi kepada produk dan jasa yang dihasilkan.

\section{Value Chain pada Pelayanan Geriatri}

Langkah-langkah dalam Analisis Rantai Nilai Analisis rantai nilai dapat dipecah menjadi tiga langkah berurutan: (1) Memecah pasar / organisasi 
ke dalam kegiatan utamanya bawah masing-masing judul utama dalam model; (2) Menilai potensi untuk menambah nilai melalui keunggulan biaya atau diferensiasi, atau mengidentifikasi kegiatan saat ini di mana bisnis tampaknya pada kerugian kompetitif; (3) Menentukan strategi dibangun sekitar fokus pada kegiatan di mana keunggulan kompetitif dapat dipertahankan. Langkah-langkahnya adalah menilai aktivitas apa yang sudah kita laksanakan dengan baik, dan apa yang belum dilaksanakan dengan baik untuk masing-masing komponen rantai nilai. Setelah kekuatan dan kelemahan organisasi diidentifikasi, masing-masing akan dinilai untuk menentukan apakah bisa menjadi sebuah keunggulan kompetitif atau malah menjadi kelemahan kompetitif.

\section{Langkah I : Mengidentifikasi kekuatan dan kelemahan internal organisasi}

Ada 3 (tiga) macam kekuatan dan kelemahan

a. Kekuatan Objektif : kekuatan yang dimiliki RS yang mudah dikenali, misal letak yg strategis, (berarti menghalangi pesaing untuk memiliki lokasi tersebut

b. Kelemahan Objektif : misalkan RS memiliki banyak pinjaman untuk membeli peralatan, dan kemudian tidak mampu untuk memperbarui teknologi.

c. Kekuatan / kelemahan Subjektif : kekuatan / kelemahan atas dasar opini seseorang yang melakukan evaluasi. Kekuatan/kelemahan relatif yang hanya dapat ditetapkan setelah dihubungkan dengan kekuatan/kelemahan kompetitor. Misal : sebuah Rumah sakit pendidikan yang besar mempunyai pelayanan spesialis yang baik dan lengkap, kemudian satu dokter bedah terbaiknya pindah ke rumahsakit swasta yang membuat unit bedah sangat canggih, Rumahsakit pendidikan tersebut tetap memiliki keunggulan dalam pelayanan yang lengkap, tetapi memiliki kelemahan relatif di bidang bedah. Keunggulan kompetitif dimiliki apabila memiliki sumberdaya yang langka dan berlimpah, kompetensi khusus, dan kemampuan manajemen (kapabilitas) yang baik .

Faktor pendukung terdiri dari :

a. Sumberdaya Bernilai, langka, mahal, susah ditiru, akan memberikan kunci untuk keunggulan kompetitif. Tidak mudah dibangun dan didistribusikan. Menerangkan kemampuan tiap Rumahsakit untuk bersaing secara efektif.

b. Organisasi dengan sumber daya superior akan memberikan generate profit pada Organisasi. Tetapi dengan sumberdaya pas pasan akan berdampak impas.paOrganisasi, sedangkan apabila dengan sumber daya kurang atau minus maka hilang

c. Kompentensi, kompetensi individu merupaka sumber keunggulan kompetitif yang lestari . Rumahsakit perlu soft kompetensi yang baik untuk mengelola manusia yang rumit dan mengkoordinasikan aktivitas pelayanan rumahsakit. Dibutuhkan persyaratan kompetensi minimal untuk bersaing dipasar, dan hanya yang paling baik yang akan menjadi unggul. (kompetensi ini akan menjadi kunci pembangunan keunggulan kompetitif yang lestari)

d. Kapabilitas adalah kemampuan organisasiuntuk mendistribusikan sumberdaya dan kompetensi (kombinasinya) untuk memproduksi pelayanan yang baik. Kapabilitas yang baik adalah sumber potensial untuk membangun keunggulan kompetitif , Kapabilitas ada 2 (dua) golongan : (1) Kemampuan untuk membuat peningkatan yang dinamis bagi organisasi, melalui pembelajaran, perubahan sepanjang waktu. Dua kemampuan untuk membangun pemikiran strategis dan mengatur sumber daya dan kompetensi untuk membangun strategi baru atau yang lebih baik dari kompetitor

\section{Langkah II : Mengevaluasi relevansi kompetitif, Identifikasi kekuatan dan kelemahan}

Melakukana evaluasi apa saja yang sudah dilakukan dengan baik dan apa saja yang belum dilakukan dengan baik. Tidak semua kekuatan/ kelemahan mempunyai relevansi kompetitif. misal : reputasi rumahsakit merupakan kekuatan, tetapi kalau reputasi kompetitor juga bagus, maka menjadi tidak relevan. Kekuatan itu harus: Memiliki nilai , Langka (jarang yg punya), Susah ditiru ,bisa dijaga kelestariannya untuk menciptakan keunggulan kompetitif . Kekuatan yang biasa biasa saja bukan sumber keunggulan kompetitif. Kekuatan harus disusun kearah terbentuknya aset strategis yang betul betul bermakna, sehingga bisa menghasilkan nilai yang lebih besar dari yang diperoleh dengan 
cara lain. Kekuatan yang biasa biasa saja bukan sumber keunggulan kompetitif. Kekuatan harus disusun kearah terbentuknya aset strategis yang betul betul bermakna, sehingga bisa menghasilkan nilai yang lebih besar dari yang diperoleh dengan cara lain. Relevansi kompetitif ditetapkan melalui jawaban dari 4 (empat) pertanyaan kritis yaitu :

1. Pertanyaan tentang Nilai Apakah sumber daya ,kompetensi, dan kapabilitas yang dipunyai menghasilkannilai bagi customer.? Jawaban : H (high) atau L (low)

2. Pertanyaan tentang kelangkaan

Apakah kita merupakan satu-satunya yang memiliki Sumber daya ,kompetensi, dan kapabilitas tersebut? Jawaban : Y (yes) atau N (no)

3. Pertanyaan tentang kemudahan untuk ditiru. Apakah sumber daya ,kompetensi dan kapabilitas tersebut mudah untuk ditiru oleh kompetitor? Jawaban : D (difficult) atau E (easy)

4. Pertanyaan tentang kesinambungan/kelestarian : Dapatkah sumber daya, kompetensi, dan kapabilitas tersebut dipelihara terus menerus? Jawaban : Y (yes) atau N (no) .

Jawaban pertanyaan no 4, bila Y, merupakan keunggulan kompetitif jangka panjang, bila jawabannya $\mathrm{N}$, merupakan keunggulan kompetitif jangka pendek saja. Apabila jawaban kombinasi
a. HY D Y = keunggulan kompetitif jangka panjang
b. HY D N = keunggulan kompetitif jangka pendek
c. HYE N = keunggulan kompetitif jangka pendek
d. HY E Y = keunggulan kompetitif jangka pendek

\section{Langkah III : Fokus pada keunggulan kompetitif Kekuatan yangmemberika kemungkinan deferensiasi bagi organisasi.}

Merupakan dasar keunggulan kompetitif yang bersifat uniqueness driver yaitu Kekuatan yang tidak memungkinkan organisasi melakukan deferensiasi, adalah dasar keunggulan kompetitif yang bersifat cost driver

Keunggulan Kompetitif Porter bahkan membagi keunggulan kompetitif inimenjadi dua jenis, yaitu
1. Cost advantage dimana sebuah perusahaan mampu menghasilkan produk atau layanan dengan manfaat yang lebih dibandingkan kompetitornya, namun dengan biaya yang lebih rendah.

2. Differentiation advantage dimana sebuah perusahaan mampu menghasilkan produk atau layanan yang memberikan value terbaik bagi penggunanya, sekaligus keuntungan yang maksimal bagi perusahaan itu sendiri. Keunikan dicirikan oleh barang dan jasa yang dihasilkan perusahaan tidak dapat mudah ditiru oleh pesaing.

\section{METODOLOGI PENELITIAN}

Jenis penelitian yang digunakan adalah penelitian deskriptif kualitatif untuk memberikan gambaran bagiamana pelaksanaan pelayanan geiatri di Rs Islam kendal mulai dari pre service, point of service serta after service. Selanjutnya dapat dikethaui bagaimana referensi kompetitifnya sehingga dapat diketahui strategi apa yangd apt ditteapkan di pelayanan geriatri

Informan utama penelitian adalah direktur, manager pelayanan, manger SDM, serta karu rawat jalan. Sedangkan yang menjadi informan triangulasinya yaitu Dokter spesialis dalam dan dokter spesialis syaraf serta perawat di masingmasing poli tersebut

Data yang diambil dalam penelitian ini adalah data primer melalui wawancara mendalam dan data sekunder melalui telaah dokumen. Setelah pengumpulan data selesai dilaksanakan maka data dianalisis menggunakan metode analisis isi (content analysis), yaitu pengumpulan data, reduksi data, dan penyajian data dan menarik kesimpulan.

\section{HASIL}

Pada tahapan pre service terliha bahwa pelayanan geriatri belum dilakukan oleh RS Islam kendal. RS Islam kendal menggunakan data penelitian yang dilakukan beberapa inStansi dan penelitian mahasiswa sebagai bahan rujukan untuk bahan pertimbangan pembuatan bisnis plan. Promosi pelayanan geriatri masih ditangani oleh tenaga tenaga sambilan belum dilakukan oleh divisi marketing . Pada tahap point of service diperoleh hasil bahwa perawat pemberi pelayanan belum bersertifikat gerontik, pasien masih ditangani oleh 
Dokter penyakit dalam dan Dokter penyakit syaraf, akan tetapi pelayanan geriatri sudah memiliki SOP yang jelas yang tertuang dalam Asuhan keperawatan.

Support activity dalam pelayanan geriatri yang terdiri dari budaya organisai yang ada sudah menunjukan budaya yang profesional dan menjiwa dengan karyawan yaitu adanya $4 \mathrm{~S}$ senyum salam sapa, Struktur Organisasi yang ada mudah dipahami dan tidak berbelit dalam memberikan pelayanan, Sumber daya yang ada baik sumber daya manusia maupun sumber daya pendukung terlaksananya pelayanan memiliki nilai yang tidak mudah dimiliki

Tabel 4.8. kekuatan dan kelemahan penciptaan Nilai pelayanan geriatri di RS Islam kendal

\begin{tabular}{|c|c|c|}
\hline $\begin{array}{l}\text { Komponen rantai } \\
\text { nilai }\end{array}$ & $\begin{array}{l}\text { Kekuatan } \\
\text { Penciptaan Nilai }\end{array}$ & $\begin{array}{l}\text { Kelemahan } \\
\text { Penciptaan Nilai }\end{array}$ \\
\hline \multirow[t]{3}{*}{$\begin{array}{l}\text { Pre service / sebelum } \\
\text { pelayanan geriatri }\end{array}$} & $\begin{array}{l}\text { Letak geografis yang } \\
\text { menguntungkan. } \\
\text { Memiliki lahan luas yang } \\
\text { memudahkan } \\
\text { untukpengembangan } \\
\end{array}$ & $\begin{array}{l}\text { Belum dilakukannya } \\
\text { penelitian pasar }\end{array}$ \\
\hline & $\begin{array}{l}\text { Sasaran pasar yang jelasTarif } \\
\text { pasien jelas }\end{array}$ & $\begin{aligned} & \text { Promosi belum dikelola } \\
& \text { secara maksimal oleh } \\
& \text { bagian marketing } \\
& \\
& \text { Belum memiliki clinical } \\
& \text { Pathway }\end{aligned}$ \\
\hline & $\begin{array}{l}\text { Struktur organisasi dan birokrasi } \\
\text { yang mudah serta menunjang } \\
\text { pelayanan }\end{array}$ & \\
\hline $\begin{array}{l}\text { Point of service / } \\
\text { Pada saat pelayanan } \\
\text { geriatri }\end{array}$ & $\begin{array}{l}\text { SOP pelayanan jelas } \\
\text { Tenaga pemberi } \\
\text { pelayanan memiliki resposifitas, } \\
\text { empati terhadap pasien }\end{array}$ & $\begin{array}{l}\text { Perawat pemberi } \\
\text { pelayanan belum } \\
\text { bersertifikat gerontik } \\
\text { Pelayanan baru } \\
\text { dilayani oleh dokter } \\
\text { spesialis syaraf dan } \\
\text { spesialis penyakit } \\
\text { dalam }\end{array}$ \\
\hline $\begin{array}{l}\text { After service / } \\
\text { sesudah Pelayanan } \\
\text { geriatri }\end{array}$ & $\begin{array}{l}\text { Pasien merasa puas dengan } \\
\text { pelayanan yang diberikan } \\
>\text { Rumah sakit care dengan pasien } \\
\text { dengan adanya pelayanan tindak } \\
\text { lanjut pelayanan } \\
>\text { Adanya komunitas } \\
\text { geriatri sebagai komunikasi } \\
\text { antar pasien }\end{array}$ & $\begin{array}{l}\text { Tidak adanya evaluasi } \\
\text { setelah melakukan } \\
\text { pelayanan } \\
\text { Komunitas geriatri } \\
\text { masih menjadi satu } \\
\text { dengan komunitas } \\
\text { lainnya }\end{array}$ \\
\hline $\begin{array}{l}\text { Support activity / } \\
\text { pelayanan pendukung }\end{array}$ & $\begin{array}{l}\text { Memilki budaya organisasi yang } \\
\text { profesional yaitu } \\
4 \mathrm{~S} \\
>\text { Sistem informatika yang sangat } \\
\text { bagus untukpengembangan } \\
\text { Sistem informasi Rumah sakit } \\
\text { DS memiliki tehnologi yang } \\
\text { baik sesuai kelasnya yaitu RS } \\
\text { tipe C } \\
\text { > RS memililki likuiditas } \\
\text { keuangan yang bagus }\end{array}$ & $\begin{array}{l}\text { Tidak adanya } \\
\text { pengakuan tentang } \\
\text { budaya organisasi } \\
\text { Tidak semua karyawan } \\
\text { paham sistem } \\
\text { informasi rumah sakit } \\
>\text { Tehnologi yang } \\
\text { dimiliki seringnya } \\
\text { tidak dikonsulkan } \\
\text { dengan usernya }\end{array}$ \\
\hline
\end{tabular}


oleh rumah sakit kompetitor, RS Islam kendal memiliki sistem informasi kesehatan yang menjadi rujukan beberapa rumah sakit komunitas.

Kekuatan RS Islam Kendal terletak pada letak geografis yang mendukung dilaksanakannya pelayanan geriatri di Rs Islam kendal, kepuasan pasien terhadap pelayanan, memiliki budaya yang profesional dalam pelayanan, serta didukung oleh sumber daya yang sesuai standar pelayanan rumah sakit type C., sedangkan kelemahan pelayanan geriatri adalah belum dilayani secara holistik artinya masih dilayani pada penyakit Dalam, Syaraf dan Rehabilitasi medik, walaupun perawat pemberi pelayanan belum bersertifikasi perawat gerontik

Kekuatan dalam relevansi kompetitif yaitu letak geografis, pengembangan pelayanan geriatri, tingkat kepuasan pelayanan geriatri yang mampu memberikan penambahan nilai dalam pelayanan strategi yang diterapkan adalah strategi differensiasi.

\section{PEMBAHASAN}

Berdasarkan wawancara dengan informan utama dan informan triangulasi memberikan hasil bahwa pada tahapan pre service, point of service serta after service terlihat bahwa pelayanan griatri meililiki nilai tambaha atau value added masingmasing tahapan, walaupun pada pre service belum dilakukan penelitian pasar dan pada point of service perawat pemberi pelayanan belum bersertifikasi perawat gerontik, akan tetapi pasien merasa puas dengan pelayanan yang diberikan di poli rawat jalan geriatri.

...walaupun staf kami dalam melakukan pelayanan belum terstandar perawat gerontik, mereka sudah terbiasa memberikan pelayanan dengan ramah, senyum dll.......IU2

....pasien yang datang rata rata menyatakan puas dengan pelayanan yang kami berikan......IT3

Budaya organisasi yang ada sebagai support activity juga memberikan value added bagi pelayan geriatri tersebut .Hasil penelitian yang dilakukan Rs Islam Kendal menunjukan bahwa budaya organisasi sudah terbentuk dengan mengutamakan pelayanan pada pasien. Orientasi pelayanan yang berfokus pada pasien inilah dapat dirasakan oleh pasien sejak mulai datang sampai akhir pelayanan. Hal ini juga menjadi kekuatan Rs Islam Kendal yang membedakan dengan rumah sakit kompetitor disekitarnya. Identifikasi kekuatan yang mampu memberikan kekuatan nilai dalam komponen rantai nilai pelayanan geriatri tidak semuanya akan menjadi sumber keunggulan kompetitif

Pertanyaan pertama merupakan pertanyaan penentu pertanyaan berikutnya. Apabila pertanyaan pertama tidak memiliki jawaban tinggi maka tidak dapat dilanjutkan dengan tiga pertanyaan selanjutnya. Sebuah kekuatan yang tidakmemilkinilai sama sekali tidak akan memiliki relevansi kompetitif. Pertanyaan kedua apakah pelayanan tersebut memiliki nilai kelangkaan yang tidak dapat dilakukan oleh kompetitor.Apabila kelangkaan nilai tersebut dimiliki oleh kompetitor maka jawabannya adalah tidak ,Apabila dikombinasikan dengan nilai kelangkaan makaakan menjadi keunggulan kompetitif.Pertanyaan ketiga untuk menjawab apakah pesaing mendapatkan kemudahan atau kesulitan untuk meniru pelayanan yang menjadi kekuatan. Apabila kekuatan ini semakin sulit untuk ditinu makaakan semakin menjadi kekuatan kompetitif dari perusahaan tersebut untuk bertahan dalam jangka panjang. Begitu juga sebaliknya apabila kekuatan tersebut mudah ditiru maka akan menjadi kekuatan kompetitif dalam jangka pendek. Kesulitan serta kemudahan dalam meniru inilah yang menentukan apakah keunggulan kompetitif itu akan menjadi keunggulan jangka panjang atau jangka pendek.

Hasil analisis perubahan nilai dari pre service, point of service serta after service yang didukung oleh budaya organissi dan sumberdaya yang ada di RS Islam kendal menunjukkan bahwa Strategi keunggulan kompetitif yang dapat diterapkan secara menyeluruh di layanan rawat jalan geriatri adalah strategi differensiasi . Adanya keunikan produk dari pelayanan geriatri sebagai bentuk pelayanan yang kreatif yang didukung dengan sumber daya yang cukup kuat dari letak geografis serta kekuatan tehnologi dan sumber daya pendukung lain akan menjadi dukungan bagi strategi Differensiasi ini. Dukungan kuat dari marketing dan riset pasar sangat dibutuhkan untuk keberhasilan dari strategi differensiasi ini sehingga mampu meningkatkan citra dari rumah sakit. 


\section{KESIMPULAN}

Simpulan penelitian ini adalah pelayanan geriatri mulai dari pre service, point of service, serta after service yang disukung dengan aktifitas pendukung mulai dari budaya, struktur organisasi, serta Sumber daya memiliki keunggulan kompetitif dan strategi yang dapat diterapkan adalah diferensiasi. Disarankan kepada manajemen untuk mengevaluasi bisnis plan dengan melakukan penelitian pasar dan perencanaan SDM marketing.

\section{DAFTAR PUSTAKA}

1. Blocher, Edward,Kung H.Chen Thomas W.lin 199, cost management A strategic emphasis enlish edition: Mc graw- hill companies Inc; 2008

2. Darmojo, Boedhi. Geriatri / Gerontologi Sekarang dan Masa Mendatang. dalam Simposium Masalah Keperawatan Penderita Lanjut Usia.Undip: Semarang; 1998.

3. Buhlmann, Samuel. Care Delivery Value Chaiuns For Opthalmic Clinic In Switzerland. Janver: memore N 126; 2009

4. E. Porter Michael. Competitive Strategi: Technique for anlizing industries and competition; 2008

5. FR, David FR. Manajemen Strategi. Jakarta: Salemba V; 2009
6. Dep Kes RI. Pedoman Pelayanan Kesehatan Usia Lanjut di Rumahsakit UmuM. Jakarta: Dir Jen Pelayanan Medik Dep Kes RI cetakan ke II; 1999

7. Firayanti, Y. Strategi Export PT. Aquarius Shrimp Pontianak Dalam Memasuki Pasar Global. Yoyakarta: Universitas Muhammadiyah; 2009

8. J, Fried Bruce. Human Resources In Healthcare: Managing For Success, Third Edition ; 2008

9. Lora, Cecera. How Do We Heal The Healthcare Value Chain. Supply Chain Insight llc; 2013

10. Irawan, W. Strategi Sumber daya Manusia Menghadapi Status Peningkatan Status Rumahsakit (Studi Kasus pada Rumahsakit Daerah Panembahan Senopati Bantul). Yogyakarta: Universitas Muhammadiyah; 2008

11. Iskandar, A. Evaluasi Strategi Pemasaran Rumahsakit Roemani Muhammadiyah Semarang. Yogyakarta: Univesitas Muhammadiyah; 2011

12. Kementerian Kesehatan Indonesia. Profil Kesehatan Indonesia 2010. Jakarta: 2011

13. Swayne, Linda e. Strateegic Mangement Of Health Care Organizations. Blackwell publishing; 2006 